\title{
Numerical Determination of Flushing Time for Stratified Water Bodies
}

K.W. Choi and J.H.W. Lee ${ }^{1}$

Department of Civil Engineering, The University of Hong Kong, Pokfulam Road, Hong Kong, China.

\begin{abstract}
:
It is often advantageous to model a semi-enclosed estuarine or coastal embayment (e.g. fish farms or tidal inlets, or typhoon shelters) as a separate system within a larger water body connected to the outer sea. The water quality of the system depends crucially on its flushing time - the average time of a particle in the system. The flushing time is governed by the barotropic and baroclinic tidal exchanges between the system and the outer sea. We describe herein a general method to determine systematically the flushing time of a stratified water body via a numerical tracer experiment. Numerical solution of the 3D flow and mass transport equations for many practical problems show that the tracer mass removal process depends on the physical topography and bathymetry, tidal range and the degree of stratification in the outer sea. Field application suggests that the tracer mass variation can be well approximated by a double-exponential decay curve that can be described by three flushing coefficients. Using a simple analytical two-segment model, the flushing coefficients can be given a clear physical interpretation, and the flushing time can be easily determined in terms of the coefficients. The method is illustrated by application to a number of tidal inlets in Hong Kong, in both the dry and wet season. The connection between the numerically determined flushing time and the traditional bulk flushing time obtained from salt balance methods is established.
\end{abstract}

Keywords: Flushing time; Tidal flushing; Density Stratification; Three-dimensional modelling; Numerical model; Tracer experiment; Water Quality.

\footnotetext{
${ }^{1}$ Correspondence to J.H.W. Lee at hreclhw@hkucc.hku.hk and fax no.: +852-2559-5337
} 


\section{Introduction}

It is often advantageous to model a semi-enclosed estuarine or coastal embayment (e.g. fish farms or tidal inlets, or typhoon shelters) as a separate system within a larger water body connected to the outer sea. The water quality of the system depends crucially on its flushing time (or its inverse, flushing rate), which is a lumped measure of the effectiveness of tidal flushing in removing any "pollutant" from the water body. For example, the occurrence of a harmful algal bloom or "red tide" in an inlet depends on the flushing rate relative to the net growth rate of an invading algal species transported into the area (Garcon et al. 1986). The local impact of specific pollution generated from fish farming activities (e.g. unconsumed fish feed, pathogenic bacteria, diseases) also depends on the flushing rate in the vicinity of the fish farm. For environmental management purposes, since many water quality processes occur at time scales much larger than that of tidal variation, hydrodynamic and water quality models can be effectively coupled by lumping all the tidal exchanges for a given system into a flushing rate. The main attractiveness of such a simplified approach is the immediate practical value of linking pollution input and ecosystem response in a tractable manner (e.g. Lee and Wong 1997).

In general, the flushing time of a given system depends on the tidal exchanges between the system and the outer sea - which is a complicated function of the freshwater runoff, tidal range, topography and bathymetry, density stratification, and wind. Tidal flushing is a commonly used term; the use of the flushing time concept for a water body can be traced back to the early fifties. It is also known as residence time, total exchange time, turnover time or detention time, but there is no unique agreed definition or method of determination. Basically it refers to the time needed for the entire volume of a specific water body to be removed through its open boundaries, but more often we are interested in the removal of the dissolved substance in the water.

Traditionally, flushing times are estimated using tidal prism or salt balance concepts (Ketchum 1951, Dyer 1973). Tidal prism methods tacitly assume complete mixing within the defined segments, and hence tend to produce overly optimistic flushing rates. More recently Luketina (1998) discusses four versions of improved tidal prism models with increasing complexity. The proposed model provides better estimation on the flushing time but full mixing is still assumed and only the bulk effect of the tidal prism is considered. The exchange characteristics of tidal inlets and marinas have also been studied using "tidal pumping" concepts (Taylor and Dean 1974; Tkalich and Chen 1997). By assuming that the flood flow entering the semi-enclosed inlet behaves like a jet, while the flow leaving the bay during ebb tide is a sink-type of flow (Stommel and Farmer 1952; Fischer et al. 1979), an analytical model of the tidal exchange characteristics between the inlet and its exterior can be obtained. However, the simple method is limited to inlets with one entrance, and for regular geometries. By the nature of the tidal prism method, density stratification and shear dispersion effects on the flushing time cannot be accounted for.

Using salinity as a tracer, the flushing time can be estimated from the estuarine geometry, and long-term average freshwater runoff and salinity measurements using the "fraction of freshwater" method (Dyer 1973; Fischer et al. 1979). This method is only applicable when detailed freshwater flow and salinity measurements are available; hence it cannot be applied to new sites. In addition, the method is prone to error when salinity gradients along the coastal inlet are small (e.g. when most of the rainwater is routed to reservoirs, resulting in negligible freshwater inflow into the sea). Guo and Lordi (2000) propose a 
modified approach to determine the total freshwater input and flushing time in an estuary using measured flow and salinity data at the estuary-ocean boundary. The main difference between the new method and the traditional method is that the water being removed on the ebb has a different salinity from the mean salinity in the estuary. The net tidal exchange is found to be a function of the flood and ebb flows, salinity of the undiluted ocean water, average salinity of the water entering the bay on the flood tide, average salinity of the flood and ebb water at the ocean-bay boundary. This method provides a more realistic estimation of the flushing time, but can be used only when reliable detailed salinity and flow measurements are available.

With the advance of numerical hydrodynamic and mass transport models, tidal flushing times have also been determined via numerical models (e.g. Prandle 1984; Choi et al. 1989; Signell and Butman 1992; Luff and Pohlmann 1995). The basic idea is that a mass of hypothetical conservative tracer is instantaneously introduced into a region of interest. A unit tracer concentration is prescribed initially inside that region, and the subsequent advective dispersion of this mass is then obtained by solving the mass transport equation numerically and the time-variation of the tracer mass inside the region is tracked. Very often, the flushing time is then taken as the time taken for the tracer mass to reduce to a certain level (such as $e^{-1}, 50 \%$ or $10 \%$ ) of the initial mass. For example, Prandle (1984) showed that under certain assumptions the flushing time is equivalent to the turnover time - the time taken for the mass level to fall to $e^{-1}$ of the initial level. In that paper the analogy between the flushing time and the residence time - the time required to travel from an initial position to the boundaries of a defined region - was also discussed.

The effect of tide and wind on the physics of flushing and the flushing time in Boston Harbour was investigated using a 2D numerical model by Signell and Butman (1992). Oliveria and Baptista (1996) proposed the use of a cumulative histogram of flushing times (for different sub-areas within the region) instead of a single flushing time. Monsen et al. (2002) used numerical tracer experiments to determine the flushing time and residence time for a shallow tidal lake. The flushing time is considered to be a system-level measure and a single value for the entire water body, while the residence time is taken as a spatially varying local measure. In both of the above studies, the particle tracking method is used to simulate the tracer mass transport and the effect of turbulent diffusion is not included. The effect of density stratification has not been studied in all of the previous numerical studies. As an alternative approach, numerical tracer experiments have also been carried out using the tidally-averaged residual circulation for the study of long term mixing time scales and water exchanges in the North Sea (Prandle 1984; Luff and Pohlmann 1995).

Despite the progress made by the previous studies, several outstanding issues on the determination of the flushing time $\left(T_{f}\right)$ remain unresolved: the dependence of $T_{f}$ on density stratification and turbulent diffusion, the determination of $T_{f}$ from the tracer mass reduction curve (e.g. time to $e^{-1}$ or $10 \%$ ), and the connection between the numericallydetermined $T_{f}$ and traditional bulk measures from salt-balance. We describe herein a general method to determine systematically the flushing time of a stratified water body via a numerical tracer experiment. The method is illustrated by the numerical solution of the 3D flow and mass transport equations for a number of practical problems; the effects of turbulent diffusion and density stratification on $T_{f}$ are discussed. It is shown that in general the tracer mass removal process is represented by a double-exponential decay curve that can be described by three flushing coefficients. Using a simple analytical two- 
segment model, the flushing coefficients can be given a clear physical interpretation, and the flushing time $T_{f}$ can be easily determined in terms of the coefficients. The connection between the numerically-determined flushing time and the traditional bulk flushing time is established.

\section{Conceptual Model of Tidal Flushing}

We first present a simple conceptual model to describe the tidal flushing of a semienclosed embayment that is situated within a larger bay that is connected to the outer sea. The model is motivated by many field application studies, and will serve as a basis for the interpretation of results of numerical tracer experiments of tidal flushing using 3D flow and transport models. Fig. 1a) shows a semi-enclosed coastal water body that is schematized as a single well-mixed system with volume $V$. The net out-going flux through the open boundaries or the renewal rate is $Q_{e}$.

The tidal flushing of a system can be studied with respect to a hypothetical tracer experiment. A mass of tracer is instantaneously introduced into the system; a unit tracer concentration is prescribed initially inside that region, and zero elsewhere. The tracer mass in the system will decrease with time as tidal advection and dispersion act to remove the tracer from the system. If the system of water is initially labelled with a conservative tracer at initial concentration $C_{o}$ and tracer mass $M_{o}$, then assuming no mass return to the system from the exterior, the decrease of tracer mass due to tidal flushing is given by:

$$
M=M_{o} e^{-k t}
$$

where $k=Q_{e} / V$.

In order to derive systematically the flushing time from numerical tracer experiments, we adopt a definition of the flushing time $T_{f}$ as "the average lifetime of a particle in the given volume of water body" (Officer and Kester 1991). For the tracer experiment, it can be represented by the following equation:

$$
T_{f}=-\frac{1}{M_{o}} \int_{o}^{\infty} t d M
$$

If the time-variation of tracer mass $M(t)$ is obtained either by experiments or numerical computation, the flushing time can be computed. For the single mixed segment, application of Eqs (2) and (1) gives the flushing time:

$$
T_{f}=k^{-1}=\frac{V}{Q_{e}}
$$

For this case the flushing time corresponds to the time when the tracer mass in the system is reduced to $e^{-1}$ of the initial level (turnover time). Hence a flushing process that can be described by Eq. 1 can be characterized by a single parameter, either $T_{f}$ or $k$. The flushing time is also equal to the time needed for the entire volume of the system to be removed 
through its open boundaries. While the volume $V$ can be readily obtained from field measurements, the net tidal exchange $Q_{e}$ is affected by many factors including freshwater runoff, tidal flow and salinity distribution, and cannot in general be directly measured. Hence, the flushing time is typically determined indirectly via salt-balance methods or numerical tracer experiments.

To study the flushing time of real tidal systems, it is advantageous to consider a simple two-segment system as shown in Fig. 1b). A semi-enclosed region of interest (denoted by system or inner segment 1) is isolated within a larger bay that is connected to the outer "clean" sea through an open boundary. We denote the tracer mass in the inner segment of volume $V_{1}$ as $M_{1}$ and the rest of the system (segment 2) of volume $V_{2}$ as $M_{2}$. Hence, the tracer concentrations are $C_{1}\left(=M_{1} / V_{1}\right)$ and $C_{2}\left(=M_{2} / V_{2}\right)$ respectively. Assuming the net tidal exchange flows between segment 1 and 2 be $Q_{12}$ and $Q_{21}$ and those between the system and the "clean ocean" be $Q_{20}$ and $Q_{02}$ respectively, the following two equations can be obtained by tracer mass conservation,

$$
\begin{gathered}
\frac{d V_{1} C_{1}}{d t}=-Q_{12} C_{1}+Q_{21} C_{2} \\
\frac{d V_{2} C_{2}}{d t}=-Q_{20} C_{2}+Q_{12} C_{1}-Q_{21} C_{2}
\end{gathered}
$$

Taking $k_{a}=Q_{12} / V_{1}, \alpha=\left(V_{1} Q_{21}\right) /\left(V_{2} Q_{12}\right)$ and $k_{c}=Q_{20} / V_{2}$, we can rewrite Eqs. (4) \& (5),

$$
\begin{gathered}
\frac{d M_{1}}{d t}=-k_{a} M_{1}+\alpha k_{a} M_{2} \\
\frac{d M_{2}}{d t}=-\left(\alpha k_{a}+k_{c}\right) M_{2}+k_{a} M_{1}
\end{gathered}
$$

By differentiating Eq. 6 with respect to time and using Eq. 7, a second-order equation in terms of $M_{1}$ can be obtained:

$$
\frac{d^{2} M_{1}}{d t^{2}}+\left(k_{a}+\alpha k_{a}+k_{c}\right) \frac{d M_{1}}{d t}+k_{a} k_{c} M_{1}=0
$$

Since $\left(k_{a}+\alpha k_{a}+k_{c}\right)^{2}-4 k_{a} k_{c}=\left(k_{a}+\alpha k_{a}-k_{c}\right)^{2}+4 \alpha k_{a} k_{c} \geq 0$, the general solution for this system of ordinary differential equations is given by (Kreyszig 1993):

$$
\begin{gathered}
M_{1}=M_{a} e^{-k_{1} t}+M_{b} e^{-k_{2} t} \\
M_{2}=\frac{M_{a}}{\alpha k_{a}}\left(k_{a}-k_{1}\right) e^{-k_{1} t}+\frac{M_{b}}{\alpha k_{a}}\left(k_{a}-k_{2}\right) e^{-k_{2} t}
\end{gathered}
$$


where, $k_{1}, k_{2}=\frac{1}{2}\left(\left(k_{a}+\alpha k_{a}+k_{c}\right) \pm \sqrt{\left(k_{a}+\alpha k_{a}+k_{c}\right)^{2}-4 k_{a} k_{c}}\right)$

Since $\left|k_{1}-k_{2}\right|=2 \sqrt{\left(k_{a}+\alpha k_{a}+k_{c}\right)^{2}-4 k_{a} k_{c}}$, so $k_{1}=k_{2}$ only when $\alpha=0$ and $k_{a}=k_{c}$. Since $\alpha$ is always greater than zero (unless a single segment is considered), we have $k_{1} \neq k_{2}$ and can assume that $k_{1}>k_{2}$ without loss of generality in the discussions below.

The above model can be used to study two general cases of flushing.

\section{“Local” flushing}

For studying the impact of any foreign substance (e.g. radioactivity from nuclear power station, invading algal species, toxic spills or effluent discharges) introduced into a region of interest, it is useful to study the "local flushing time". This flushing time is determined based on the tracer mass removal from a small local region into its immediate adjacent 'clean' environment.

To determine the "local" flushing from segment 1 only, we apply the initial conditions that when $t=0, M_{1}=M_{o}$ and $M_{2}=0$,

$$
\begin{aligned}
& M_{1}=M_{o}\left(\frac{k_{a}-k_{2}}{k_{1}-k_{2}} e^{-k_{1} t}+\left(1-\frac{k_{a}-k_{2}}{k_{1}-k_{2}}\right) e^{-k_{2} t}\right) \\
& M_{2}=\frac{M_{o}\left(k_{a}-k_{1}\right)\left(k_{a}-k_{2}\right)}{\alpha k_{a}\left(k_{1}-k_{2}\right)}\left(e^{-k_{1} t}-e^{-k_{2} t}\right)
\end{aligned}
$$

Eq. 11 indicates that the tracer mass reduction inside segment 1 is represented by a double exponential decay curve in the following form:

$$
\frac{M}{M_{o}}=\gamma e^{-k_{1} t}+(1-\gamma) e^{-k_{2} t}
$$

in which the three flushing parameters $\gamma, k_{1}$ and $k_{2}$ are related to the segment volumes and tidal exchange flows. Conversely, if these parameters can be determined from a computed tracer mass removal curve (e.g. from 3D calculation of a tracer experiment), the system characteristics measured by $V_{1}, V_{2}, Q_{12}$ and $Q_{20}$ can also be inferred.

Eq. 13 shows that the mass reduction process is described by a two-stage process instead of a simple exponential decay. Without loss of generality, we can assume that $k_{1} \geq k_{2}$, with $k_{1}$ representing the flushing rate for the more rapid removal stage, while $k_{2}$ represents the rate for the slower stage. Using the definition in Eq. 2, the flushing time of segment 1 can be shown to be: 


$$
T_{f}=\frac{\gamma}{k_{1}}+\frac{1-\gamma}{k_{2}}
$$

and can be interpreted in terms of the system characteristics:

$$
\left(T_{f}\right)_{1}=\left(\frac{k_{a}-k_{2}}{k_{1}-k_{2}}\right) \frac{1}{k_{1}}+\left(\frac{k_{1}-k_{a}}{k_{1}-k_{2}}\right) \frac{1}{k_{2}}
$$

Since $k_{1}+k_{2}=k_{a}+\alpha k_{a}+k_{c}$ and $k_{1} k_{2}=k_{a} k_{c}$, we can simplify Eq. 15 to

$$
\left(T_{f}\right)_{1}=\frac{1}{k_{a}}+\frac{\alpha}{k_{c}}=\frac{V_{1}}{Q_{12}}+\frac{V_{1}}{Q_{20}}
$$

Again, it is of the same form as Eq. 1 and represents how well the pollutant is removed into its immediate neighbourhood and subsequently carried away into the "clean ocean". Eq. 16 indicates that the flushing time is governed by both the exchange flow between the local region and its surrounding water as well as that between the whole system and the "clean" exterior. Note that Eq. 14 suggests that the flushing time is solely dependent on the characteristics of the tracer mass removal curve - namely the three flushing parameters $\gamma, k_{1}$ and $k_{2}$.

\section{"System-wide" flushing}

For predicting many water quality parameters such as salinity, nutrient, and biochemical oxygen demand, the surrounding water may have a non-zero concentration due to the return of the pollutant with the tide. To estimate the long-term average water quality, an alternative measure of flushing, the "system-side" flushing time is preferred. This is determined by considering the tracer mass removal from a much larger water body that is connected to an adjoining "clean" ocean; i.e. for this system whatever pollutant removed will unlikely return.

To find the "system-wide" flushing time for both segment 1 and 2, we assume that both segments are assigned a unit initial concentration, i.e. when $t=0, M_{1}=M_{\mathrm{o}}$ and $M_{2}=M_{\mathrm{o}} / \alpha$. The solution to Eqs.(6) \& (7) is

$$
\begin{gathered}
M_{1}=M_{0}\left(\left(1+\frac{k_{2}}{k_{1}-k_{2}}\right) e^{-k_{2} t}-\frac{k_{2}}{k_{1}-k_{2}} e^{-k_{1} t}\right) \\
M_{2}=\frac{M_{o}}{\alpha}\left(\left(1+\frac{k_{2}\left(k_{a}-k_{1}\right)}{k_{a}\left(k_{1}-k_{2}\right)}\right) e^{-k_{2} t}-\frac{k_{2}\left(k_{a}-k_{1}\right)}{k_{a}\left(k_{1}-k_{2}\right)} e^{-k_{1} t}\right)
\end{gathered}
$$

By re-arranging the terms, both of these equations can again be expressed in form of a double exponential decay curve: 


$$
\frac{M}{M_{o}}=(1+\beta) e^{-k_{2} t}-\beta e^{-k_{1} t}
$$

It can be seen that the tracer mass removal for both segments depends on the three flushing parameters, $\beta, k_{1} \& k_{2}$, which can be interpreted in terms of the segment characteristics and tidal exchange flows from Eq. 17 and Eq. 18. If the flushing parameters can be determined from the computed tracer mass removal curve in a tracer experiment, the flushing time according to Eq. 2 can be then be computed from these coefficients as:

$$
T_{f}=\frac{1+\beta}{k_{2}}-\frac{\beta}{k_{1}}
$$

In the same way as described above, the "system-wide" flushing time for the two segments can be expressed in terms of the tidal exchange flows and bay geometry parameters:

$$
\begin{aligned}
& \left(T_{f}\right)_{1}=\frac{k_{1}}{k_{2}\left(k_{1}-k_{2}\right)}-\frac{k_{2}}{k_{1}\left(k_{1}-k_{2}\right)}=\frac{V_{1}}{Q_{12}}+\frac{V_{1}+V_{2}}{Q_{20}} \\
& \left(T_{f}\right)_{2}=\frac{k_{1}\left(k_{a}-k_{2}\right)}{k_{a} k_{2}\left(k_{1}-k_{2}\right)}-\frac{k_{2}\left(k_{a}-k_{1}\right)}{k_{a} k_{1}\left(k_{1}-k_{2}\right)}=\frac{V_{1}+V_{2}}{Q_{20}}
\end{aligned}
$$

From these two equations, it can be seen that the "system-wide" flushing time for segment 2 is the same as that for a well-mixed system and is cumulative from the open water towards the inner segment.

This measure of flushing time accounts for the interactions between different parts of the water body that is not assumed to be "clean", and represents the long-term flushing efficiency of the region of interest. It is similar to the traditional approach of determining the flushing time using salinity (or freshwater concentration) as the tracer, but the approach is applicable even for cases when salt balance methods cease to apply: negligible freshwater runoff, weak longitudinal salinity gradients, or when detailed salinity data are lacking. The "system-wide" flushing time is suitable for determining the long-term water quality and hence the carrying capacity of a given tidal inlet (e.g. to assess the suitability of a given site for fish farming). By applying different initial tracer distributions, both the "local" and "system-wide" flushing time can be computed from the tracer experiments.

It should be pointed out that the tracer mass removal (or reduction) curve for the region of interest is actually equivalent to the cumulative histogram of flushing time proposed by Oliveria and Baptista (1996).

\section{Flushing Time and the Tracer Experiment Approach}

The above simple model provides an analytical basis for deriving the flushing time from numerical tracer experiments. Typically we are interested to determine the flushing time of a tidal inlet situated within a larger water body that is connected to the open sea. The flow 
field of the entire system (larger water body containing the tidal inlet) can be determined using 3D tidal flow models; both tidal forcing, gravitational circulation and wind stress effects can be taken into account. With the computed flow field, numerical tracer experiments can then be carried out to simulate the tracer mass transport processes. We first summarize several salient points of the tracer mass removal process in typical tidal inlets before proceeding to presenting detailed application examples.

\section{Tracer mass removal in coastal bays}

Fig. 2 shows the computed tracer mass removal process for a marine fish farm located at the inner end of a coastal bay in Hong Kong (Sok Kwu Wan fish culture zone, see Fig. 6 and later discussion). The 3D stratified flow under typical tidal and salinity boundary conditions is first computed. Using the repeating tidal flow field, the fish farm is labelled with unit concentration of a conservative tracer, and the subsequent evolution of the tracer concentration field in the entire Sok Kwu Wan is obtained by solving the mass transport equation. The tracer mass within the region of interest (the fish farm) can then be computed as a function of time. It can be observed that the tracer mass in the fish farm decreases as the "pollutant" is continuously removed by the flood and ebb of tides, and varies with the tidal phase. The complicated mass removal process is characterized by an initial rapid fall off followed by a slower decay phase; the overall two-stage removal process is better represented by a double exponential decay curve (solid line in Fig. 2 to Fig. 4) than the usually adopted simple exponential decay for a single well mixed semienclosed bay. The three flushing parameters $\left(\gamma, k_{1}\right.$ and $\left.k_{2}\right)$ for the double exponential equation (Eq. 13) can be uniquely determined numerically by least square curve fitting, from which the flushing time of the system can be evaluated (Eq. 14).

A key advantage of using the tracer experiment to determine the flushing time over the conventional methods is that it is applicable to stratified water bodies. As shown in Fig. 2, the flushing due to tidal forcing alone, which can be obtained from solving just the 2D depth-averaged constant density (barotropic) flow, can be much slower than the flushing due to the 3D density-induced circulation. For this case, the flushing time in the presence of stratification (wet season) is considerably smaller than in constant density flow (0.4 days versus 9 days).

Fig. 3 shows the tracer mass removal process for the dry season for the same site. The effect of turbulent diffusion on the flushing process is illustrated. It can be seen that exclusion of the turbulent dispersion terms in the tracer mass transport equation does not result in noticeable differences in the first few hours during which the tracer transport is entirely advection-dominated. However the overall removal process and the computed flushing times with and without the turbulent diffusion can be significantly different (3.8 days versus 16.9 days).

The double-exponential decay representation of tidal flushing can also be noted from the experimental (physical or numerical) data of other investigators. Fig. 4a) shows a schematic diagram of a laboratory experiment to determine the residence time of pollutants introduced into semi-enclosed rectangular typhoon shelters ( $\mathrm{Li}$ and Ip 1999). A rectangular basin, a model of a typhoon shelter, of plan dimension $L \times W$ is placed in a laboratory flume with a uniform external flow $U$. The typhoon shelter is typically separated from the main flow by a breakwater. The rectangular basin, which is connected 
to the external flow via a narrow entrance of width $l_{w}$, is initially dyed with a Rhodamine $\mathrm{B}$ tracer at uniform concentration, and the subsequent change in dye concentration in the typhoon shelter due to turbulent and momentum exchange with the outside flow was measured. Fig. 4b) shows the result of two experiments. It can be seen that the tracer mass removal in the semi-enclosed rectangular basin is two-staged; the experimental data on the tracer mass removal is much better represented by the double exponential decay than a single exponential decay (best fit or exponential decay with enforced initial condition). Similar statements can be made on the numerical model results given in Oliveria and Baptista (1996) - the computed tracer mass removal is well-represented by the double exponential decay curve (Fig. 5).

In addition, from Fig. $2 \& 3$, it can be seen that if the flushing time is taken as the time for the mass level to fall to $e^{-1}$ of the initial level $\left(T_{e}\right)$, it does not cater for the return of the tracer under the tidal action, so it may be much smaller than that obtained from the double exponential decay representation as described below. For example, in Fig. 2, $T_{e}=0.1$ days versus $T_{f}=0.4$ days, while in Fig. $3, T_{e}=0.25$ days versus $T_{f}=3.8$ days.

\section{Field Application: Case Studies}

The method described above has been successfully applied to study the tidal flushing of a number of fish culture zones in Hong Kong, with the objective of developing robust quantitative methods of environmental management (Choi 2002). The Sok Kwu Wan fish culture zone will first be used as an example to demonstrate how the "local" and "systemwide" flushing time is determined for an actual tidal inlet. The idea of "system-wide" flushing time is then illustrated using four fish culture zones located in Tolo Harbour.

Hong Kong is located at the mouth of the Pearl River Estuary along the South China coast. Due to freshwater inflow from the Pearl River, solar radiation and oceanic currents, there are significant vertical variations of salinity and temperature; density stratification is significant in Hong Kong's coastal waters especially during the wet season (from April to September). For the average wet season, the vertical salinity differential is around 3 to 4 parts per thousand (ppt), while for average dry season, it is only a few tenths of a ppt. Therefore, the flow circulation and flushing for the coastal bays in Hong Kong have to be studied using three-dimensional numerical models.

The hydrodynamic model developed solves the full 3D hydrodynamics equations with the hydrostatic assumption. A uniform rectangular grid is applied in the horizontal directions and a topographically conformal co-ordinate (sigma-coordinate) system is applied in the vertical direction. Similar to the Princeton Ocean Model (Mellor 1998), the model employs the modal splitting technique. For the external mode simulation, the vertically integrated continuity and momentum equations are solved by an alternating direction implicit (ADI) finite difference scheme. For the internal mode simulation, the threedimensional horizontal momentum and solute transport equations are solved by a split step scheme. A backward tracking characteristic method is employed to compute the advective motion, while central differencing in both space and time is adopted for simulating the diffusion. Vertical exchange is modelled by a mixing length approach corrected as a function of the Richardson number. This simpler approach is found to be adequate in describing the reduction of mixing due to vertical density stratification for the purpose of the present study. The numerical model has been validated against a series of laboratory 
tidal flume test results on the salinity intrusion in a partially or well-mixed estuary (Ippen and Harleman 1961; Thatcher and Harleman 1972) and also against field data (Choi 2002, Choi et al. 2003).

The mass transport model for determining local flushing is based on the Lagrangian particle tracking approach. Forward particle tracking is used to compute the advective movement, while a random walk method is used for modelling the diffusive movement. Typically, around 20,000 particles are used to obtain stable results. For system-wide flushing, as there is no sharp concentration gradient and hundreds of thousands particles will be needed, a 3D finite difference model is employed instead. It employs a massconserved, flux-corrected scheme for computing advective transport and central differencing for modelling the diffusion processes. To ensure that the finite difference model can serve as a valid alternative to the Lagrangian particle model for the systemwide flushing computation and provides a similar level of accuracy, test cases to compute flushing times for both idealized and real world basins have been carried out using both mass transport models, and the flushing times computed by the two models are found to differ by at most $10 \%$ and on average around $4 \%$ (Choi 2002).

\section{Sok Kwu Wan}

Sok Kwu Wan is located at the eastern shore of Lamma Island in the western Hong Kong Waters. It is about $4 \mathrm{~km}$ long, $0.5 \mathrm{~km}$ wide at the inner bay and $2.3 \mathrm{~km}$ wide at its mouth (Fig. 6); the water depth varies from 4 to $20 \mathrm{~m}$. A fish culture zone is located in the relatively well-sheltered inner bay.

The model grid in the horizontal plane and the particular segments under consideration for a flushing study are shown in Fig. 6. The model grid that is used in the flow and mass transport simulation consists of square cells of size $50 \mathrm{~m}$ and is subdivided into eight uniform vertical layers. The model has been verified against field data (Choi et al. 2003). For computing the tidal flushing under averaged seasonal conditions, the 3D stratified flow in the bay subject to a prescribed average M2 tide of $1.7 \mathrm{~m}$ and piecewise linear vertical salinity profile (based on field measurements) at the open boundary is computed. Both the average wet and dry season conditions have been examined. For the purpose of illustration, the "local" and "system-wide" flushing times of the innermost segment (segment 1 in Fig. 6) are determined from the mass removal curves obtained from the mass transport model. For "local" flushing, numerical tracers of unit concentration are released instantaneously from the grid cells within segment 1 only. For "system-wide" flushing, the tracers are introduced throughout the entire modelled domain. For both cases, the tracer mass in the grid cells within segment 1 (or any region of interest) is summed. By tracking the tracer mass, the time variation of mass inside the segment (i.e. the mass removal curve) will provide information about the flushing or mass removal processes. The mass removal curves for the dry season cases are shown in Fig. 7. It is seen that "system-wide" flushing can also be described by a two-stage process. The initial variation of tracer mass in segment 1 is very slow, followed by a more rapid decay.

The double exponential decay curve representing the mass reduction can be readily obtained using Quasi-Newton Least Squares method (for the present study, KyPlot is used for the curve fitting). The corresponding flushing times and $T_{e}$ are given in Table 1, and it can be seen that $T_{e}$ is a good approximation for the "system-wide" flushing but not the 
"local" one. From Fig. 7, it can be observed that when the whole bay is filled with mass, there is no net mass removal from the selected segment during the first three or four days. On the other hand, if the tracer is released only from within the segment initially, the concentration levels drop very rapidly to around $e^{-1}$ after the first tidal cycle. This shows that the two types of tracer experiment and the corresponding flushing times would provide information on the extreme conditions for the flushing processes. Both are important parameters in coastal environmental management. It can be seen that for this particular bay, there is a dramatic difference in flushing time in the dry and wet seasons. The flushing time in the wet season is almost an order of magnitude less than that in the dry season (Choi and Lee 2002). This interesting phenomenon is related to the existence of a strong downwelling in the inner part of the bay and a three-layer circulation pattern in the outer part for the wet season as shown in Fig. 8; details of this circulation will be separately reported.

The system-wide flushing time obtained using the 3D model based on the zeroth order turbulence closure can be contrasted with that obtained using an alternative 3D model with two-equation turbulence closure - the Delft3D model (Delft Hydraulics 1998). This model employs a boundary-fitted co-ordinate system and standard $k$ - $\varepsilon$ model for turbulence closure, and has been calibrated for Hong Kong waters (Lee and Qu 2004). Although the two sets of codes employ quite different formulations and numerical schemes, it is found that the flushing times determined by both models differed by less than $2 \%$ for the dry season, with an average discrepancy of around $6 \%$ for the wet season (Table 1). The system-wide flushing time computed by Delft3D is 26.0 days and 3.2 days for the dry and wet season respectively. This suggests that an integral parameter such as tidal flushing rate is less dependent on the details of the instantaneous flow conditions. If the major characteristics of the water body, including its topography, bottom bathymetry, typical tidal conditions and salinity distributions, are properly modelled, a consistent estimate for the flushing time can be obtained.

\section{Tolo Harbour}

Tolo Harbour is a nearly land-locked tidal estuary in the northeastern part of New Territories, Hong Kong. It has an area of about $50 \mathrm{~km}^{2}$ and extends about $20 \mathrm{~km}$ from southwest to northeast with an entrance width of less than $1.5 \mathrm{~km}$. The elongated inlet, Tolo Channel, connects the inner bay to the open water, Mirs Bay. The water depth at the entrance is about $25 \mathrm{~m}$, and tapers off to about 2-3 $\mathrm{m}$ in the inner reaches, where the towns of Shatin and Taipo are located. There are four marine fish culture zones (FCZs) in Tolo Harbour, they are Yung Shue Au (YSA), Yim Tin Tsai (YTT), Yim Tin Tsai East (YTTE) and Lo Fu Wat (LFW) (Fig. 9).

To study the hydrodynamic circulation and "system-wide" flushing for these FCZs, the entire Tolo Harbour is modelled. A regular square grid of size $500 \mathrm{~m}$ and 8 uniform vertical sigma layers is used. The grid is oriented in such a way that the $\mathrm{x}$-axis is approximately parallel to Tolo Channel, and it can satisfactorily represent the shoreline configuration. The model is validated against the measured tidal levels and vertical current profiles from a geophysical survey conducted in August 1978 (Choi 2002). To study the flushing under averaged seasonal conditions, mean semi-diurnal M2 tide and vertical salinity and temperature profiles are applied at the open boundary. Averaged freshwater runoff discharges are introduced into Shatin, Taipo, Plover Cove and Three Fathoms 
Cove. The computed salinity and temperature profiles compare well with long-term water quality monitoring data (Choi 2002, Lee et al. 2003). Fig. 10a) shows the peak ebb flow velocity in the wet season in the upper layer (average of top $3 \mathrm{~m}$ ) and the lower layer (below $3 \mathrm{~m}$ ). Consistent with the field data, the velocity decreases from around $0.3 \mathrm{~m} / \mathrm{s}$ in Tolo Channel to a few $\mathrm{cm} / \mathrm{s}$ in the inner harbour. The velocity difference between the upper and lower layer increases from around $0.04 \mathrm{~m} / \mathrm{s}$ in the inner harbour to over $0.1 \mathrm{~m} / \mathrm{s}$ in the channel. Fig. 10b) shows the tidally averaged x-velocity along a longitudinal transect in the wet season, a two-layer circulation flow structure can be observed.

To assist the assessment of the "system-wide" flushing characteristics, the grid cells of the model are grouped into 14 segments as shown in Fig. 11. A unit concentration of tracer is released initially in all the grid cells. The tracer mass variation in each segment is tracked by summing up the mass in each grid cell in that segment at regular time intervals. By a least square method, the mass removal process in each segment is represented by a double exponential decay curve, from which the flushing time can be computed.

The tracer mass reduction curves for the "system-wide" flushing in the segments containing the FCZs are shown in Fig. 12. The mass removal curves for segment 2, 4 and 8 are very similar in the wet season (Fig.12a) and become quite different in the dry season (Fig.12b). Segment 2 in the innermost part of Tolo has the slowest mass reduction. The corresponding flushing times (local and system-wide) obtained from those curves are listed in Table 2. In previous studies by Preston (1975) using measured long-term average salinities and average freshwater runoff, the water residence time or flushing time in the inner harbour (segments 2 and 3) is estimated to range from 16 to 36 days, which agrees well with the system wide flushing time obtained from the present study ranging from 14 to 38 days. It is also interesting to note that the effect of density-induced circulation decreases the flushing time by about a factor of 2-3 in this harbour.

Finer grid $(50 \mathrm{~m} \times 50 \mathrm{~m})$ models have also been used to study the local flushing for each FCZ in Tolo Harbour. The flushing times are computed from the tracer experiments conducted using the Lagrangian particle tracking model. As shown in Table 3, the local flushing time is more correlated with the local physical characteristics of individual embayments, and shows greater variation among them. The results again show that $T_{e}$ is not a good measure for the local flushing time.

\section{Conclusions}

For environmental management purposes it is often advantageous to model a semienclosed tidal inlet or coastal embayment as a separate system within a larger water body connected to the open sea. The impact of any polluting discharge (e.g. radioactivity, toxic spill, fish farm waste) introduced into the system depends crucially on its flushing time an integrated parameter that measures the effectiveness of tidal flushing in removing the pollutant from the system.

A systematic procedure to determine the flushing time of a semi-enclosed stratified water body using 3D numerical flow and transport models has been presented. It is shown that the flushing of a pollutant from such tidal inlets can be well represented by a double exponential decay curve that is characterized by three flushing parameters. Such a flushing mechanism can also be derived from an analytical two-segment model. The coefficients of 
the double exponential decay curve can be interpreted in terms of the tidal exchange flows and bay geometry, and can be determined numerically from results of 3D numerical simulation by least square fitting. The flushing time for the fish farm can then be directly computed from these flushing coefficients. It is shown that in general two types of flushing times can be defined. The local flushing time serves a good measure of the residence time of a foreign substance introduced into the system, while the system-wide flushing time is useful for determining long-term water quality. Density stratification has a remarkable effect on tidal flushing; typical flushing rates can be 2 to 10 times greater in the presence of density-induced circulation. The system-wide flushing time corresponds to the traditional bulk residence time obtainable by salt-balance methods. It is found the time taken for the tracer mass level within the region of interest to reduce to $e^{-1}$ of the initial value is a good approximation to the system-wide flushing time, but not the local flushing time. The generally applicable method has been applied to six tidal inlets in Hong Kong and can be coupled with eutrophication models to determine the carrying capacity of fish farms (Lee et al. 2003).

The dispersal of matter in a system is governed in the long term by the tidally-averaged residual circulation. It should be pointed out that similar estimates of flushing times for relatively large areas ("boxes") in the open sea have previously been made using the residual circulation computed from ocean models. The present study differs from the earlier oceanographic studies in several ways. First, the use of the residual circulation necessitates the use of artificially large values for the tidal dispersion coefficients - which need to be obtained by calibration against extensive tracer data (Prandle 1984). The present real time 3D calculation for complicated coastal flows circumvents the need for additional modelling or adjustment of the tidally-averaged dispersion. Second, the oceanographic flushing times (Prandle 1984; Luff and Pohlmann 1995) were computed by performing essentially a "local flushing" tracer experiment. As such, it is not surprising that these flushing times may differ from conventional bulk estimates by a factor of 2-3, although this discrepancy has been attributed to the structure of the flow field (Luff and Pohlmann 1995). Third, the effect of the gravitationally-induced circulation on the flushing time has hitherto not been quantified.

\section{Acknowledgements}

This study was supported by the Hong Kong Environment and Conservation Fund (ECF) and in part by a grant under the National Natural Science Foundation of China (NSFC)/Hong Kong Research Grants Council (RGC) Joint Research Scheme.

\section{References}

Choi, K.W., (2002). Environmental management of mariculture in Hong Kong. Ph.D. thesis, The University of Hong Kong.

Choi, K.W. and Lee, J.H.W., (2002). "Three-layer circulation and flushing of Sok Kwu Wan, Hong Kong”, Hydroinformatics 2002, Volume one: Model Development and Data Management, (edited by R.A. Falconer, B. Lin, E.L. Harris and C.A.M.E. Wilson). IWA Publishing, 476-481.

Choi, K.W., Lee, J.H.W., and Cheung, Y.K., (1989). “A numerical study of tidal flushing 
in a typhoon shelter", Proc., 4th Asian Fluid Mech. Congress, Vol. 1, (edited by N.W.M. Ko and S.C.Kot), B32-B35.

Choi, K.W., Lee, J.H.W. and Wong, K.T.M., (2003). "Field verification of diffusioninduced circulation in Sok Kwu Wan, Hong Kong”, Proc. International Conference on Estuaries and Coasts, Nov. 9-11, 2003, Hangzhou, China, Zhejiang University Press, 663670.

Delft Hydraulics, (1998). "Upgrading of the Water Quality and Hydraulic Mathematical Models: Final Model Calibration and Validation Report", Technical Services Division, Civil Engineering Office, Hong Kong Government, 21 pp.

Dyer, K.R., (1973). Estuaries - a physical introduction, John Wiley \& Sons, New York, $140 \mathrm{pp}$.

Fischer, H.B., List, E.J., Koh, R.C.Y. Imberger, J., and Brooks, N.H., (1979). Mixing in Inland and Coastal Waters, Academic Press, San Diego.

Garcon, V.C., Stolzenbach, K.D. and Anderson, D.M., (1986). "Tidal flushing of an estuarine embayment subject to recurrent dinoflaggelate blooms", Estuaries, Vol.9, No.3, 179-187.

Guo, Q., and Lordi, G.P., (2000). "Method for quantifying freshwater input and flushing time in estuaries", J. Envir. Engrg., ASCE, Vol. 126, No. 7, 675-683.

Ippen, A.T. and Harleman, D.R.F., (1961). One-dimensional Analysis of Salinity Intrusion in Estuaries, Technical Bulletin No. 5, Committee on Tidal Hydraulics, Corps of Engineers, U.S. Army, 52 pp.

Ketchum, B.H., (1951). "The exchanges of fresh and salt waters in tidal estuaries", J. Mar. Res., Vol. 10, No. 1, 18-38.

Kreyszig, E., (1993). Advanced Engineering Mathematics, 7th Edition, John Wiley \& Sons, Inc., New York, 1271 pp.

Lee, J.H.W and Qu, B., (2004). "Hydrodynamic tracking of the massive spring 1998 red tide in Hong Kong", Journal of Environmental Engineering, ASCE (in press)

Lee, J.H.W. and Wong, P.P.S., (1997). "A water quality model for mariculture management", Journal of Environmental Engineering, ASCE, Vol.123, No.11, 1136-1141.

Lee, J.H.W., Choi, K.W. and Arega, F., (2003). "Environmental management of marine fish culture in Hong Kong", Marine Pollution Bulletin, Vol. 47, Nos. 1-6, 202-210.

Li, C.W. and Ip, K.W., (1999). "Residence time in semi-enclosed water bodies", Proc. Civil and Environmental Conference, New Frontiers and Challenges, 8-12, Nov., 1999, Bangkok, Thailand, VI-13 - VI-16. 
Luff, R. and Pohlmann, T., (1995). "Calculation of water exchange times in the ICESboxes with a Eulerian dispersion model using a half-life time approach", Deutsche Hydr. Zeitschr., Vol. 47, 287-299.

Luketina, D., (1998). "Simple tidal prism models revisited", Estuarine, Coastal and Shelf Science, Vol. 46, 47-84.

Mellor, G.L., (1998). Users Guide for a Three-dimensional, Primitive Equations, Numerical Ocean Model, Princeton University, Princeton, NJ, 38 pp.

Monsen, N.E., Cloern, J.E. and Lucas, L.V., (2002). "A comment on the use of flushing time, residence time and age as transport time scales", Limnology and Oceanography, Vol. 47, No. 5, 1545-1553.

Officer, B.C. and Kester, D.R., (1991). "On estimating the non-advective tidal exchanges and advective gravitational circulation exchanges in an estuary", Estuarine, Coastal and Shelf Science, Vol. 32, 99-103.

Oliveira, A. and Baptista, A.M., (1996). "Diagnostic analysis of estuarine residence times", Computational Methods in Water Resources XI - Volume 2: Computational Method in Surface Flow and Transport Problems, (edited by A.A. Aldama, J. Aparicio, C.A. Brebbia, W.G. Gray, I. Herrera and G.F. Pinder), Computational Mechanics Publication, Southampton, 355-362.

Prandle, D., (1984). "A modelling study of the mixing of ${ }^{137} \mathrm{Cs}$ in the seas of the European continental shelf”, Phil. Trans. R. Soc. Lond. A, Vol. 310, 407-436.

Preston, J.R., (1975). "An account of investigations carried out into marine pollution control needs in Hong Kong with particular reference to the existing and future urban centres centred about Victoria and Tolo Harbour", Proc. Pacific Science Association Spec. Symp. on Marine Science, (edited by B. Morton), Government Printer, Hong Kong, 91-94.

Signell, R.P. and Butman, B., (1992). "Modelling tidal exchange and dispersion in Boston Harbour", Journal of Geophysical Research - Oceans, Vol. 97 (C10), 15591-15606.

Stommel, H. and Farmer, H.G., (1952). "On the nature of estuarine circulation", Part II, Woods Hole Oceanographic Institution, Tech. Rep. WHOI-52-51, Woods Hole, Massachusetts, USA, $131 \mathrm{pp}$.

Taylor, R.B. and Dean, R.G., (1974). "Exchange characteristics of tidal inlets", Proc. $14^{\text {th }}$ ASCE Coastal Engineering Conference, 2268-2289.

Thatcher, M.L. and Harleman, D.R.F., (1972). A Mathematical Model for the Prediction of Unsteady Salinity Intrusion in Estuaries, Report No. 144, Ralph M. Parsons Laboratory for Water Resources and Hydrodynamics, Department of Civil Engineering, Massachusetts Institute of Technology, Cambridge, Massachusetts, 232 pp.

Tkalich, P. and Chen, C.N., (1997). "A Generalized method for characterizing tidal flushing in a semi-enclosed basin", Environmental and Coastal Hydraulics: Protecting the Aquatic Habitat, Vol. 1, Proceedings of Theme B, $27^{\text {th }}$ Congress of the International 
Association for Hydraulic Research, (edited by S.S.Y. Wang and T.J. Carstens), ASCE, 713-718. 
Table 1. Computed "local" and "system-wide" flushing time of inner Sok Kwu Wan

\begin{tabular}{|l|l|l|l|l|}
\hline Flushing time & Season & $T_{f}$ (days) & $T_{e}$ (days) & Model \\
\hline \multirow{3}{*}{ Local } & Dry & 3.8 & 0.25 & HKU \\
\cline { 2 - 5 } & Wet & 0.4 & 0.08 & HKU \\
\hline \multirow{4}{*}{ System-wide } & \multirow{2}{*}{ Dry } & 25.8 & 25.4 & HKU \\
\cline { 2 - 5 } & \multirow{2}{*}{ Wet } & 26.0 & 25.9 & Delft3D \\
\cline { 3 - 5 } & & 3.5 & 3.6 & HKU \\
\cline { 2 - 5 } & 3.2 & 3.5 & Delft3D \\
\hline
\end{tabular}

Table 2. Computed "system-wide" flushing time for FCZs in Tolo Harbour

\begin{tabular}{|l|c|c|c|c|}
\hline \multirow{2}{*}{ Flushing time (days) } & \multicolumn{2}{|c|}{ Wet season } & \multicolumn{2}{c|}{ Dry season } \\
\cline { 2 - 5 } & $T_{f}$ & $T_{e}$ & $T_{f}$ & $T_{e}$ \\
\hline Yung Shue Au & 14.2 & 13.7 & 23.6 & 22.7 \\
\hline Yim Tin Tsai East & 14.8 & 14.5 & 27.2 & 27.3 \\
\hline $\begin{array}{l}\text { Yim Tin Tsai } \\
\text { (segment 2) }\end{array}$ & 14.4 & 13.9 & 38.0 & 37.0 \\
\hline Lo Fu Wat & 7.1 & 6.3 & 15.8 & 12.0 \\
\hline
\end{tabular}

Table 3. Computed "local" flushing time for FCZs in Tolo Harbour

\begin{tabular}{|l|c|c|c|c|}
\hline \multirow{2}{*}{ Flushing time (days) } & \multicolumn{2}{|c|}{ Wet season } & \multicolumn{2}{c|}{ Dry season } \\
\cline { 2 - 5 } & $T_{f}$ & $T_{e}$ & $T_{f}$ & $T_{e}$ \\
\hline Yung Shue Au & 6.4 & 0.5 & 8.6 & 1.5 \\
\hline Yim Tin Tsai East & 3.3 & 0.6 & 4.9 & 0.9 \\
\hline Yim Tin Tsai & 2.7 & 0.2 & 3.3 & 0.3 \\
\hline Lo Fu Wat & 0.4 & 0.05 & 0.8 & 0.09 \\
\hline
\end{tabular}




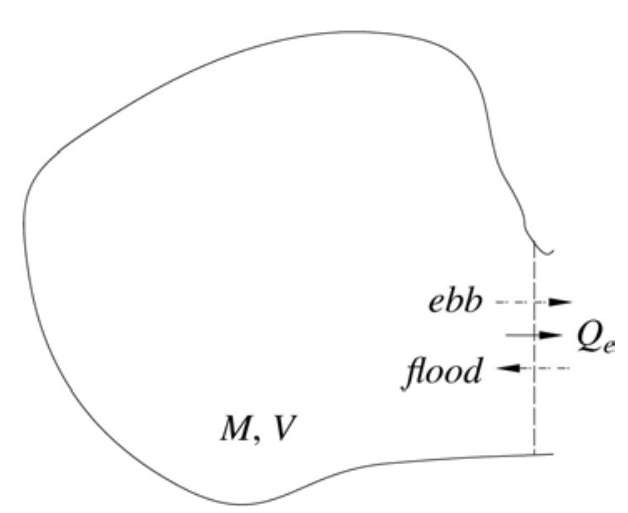

(a)

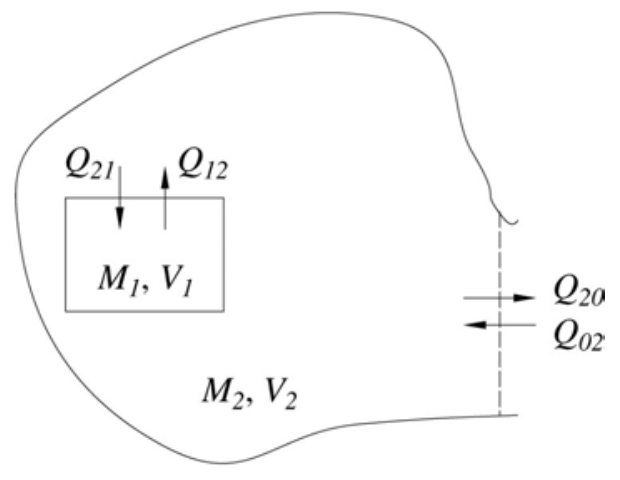

(b)

Fig. 1. Schematic diagram for flushing analysis of a semi-enclosed water body: (a) onesegment system; (b) two-segment system

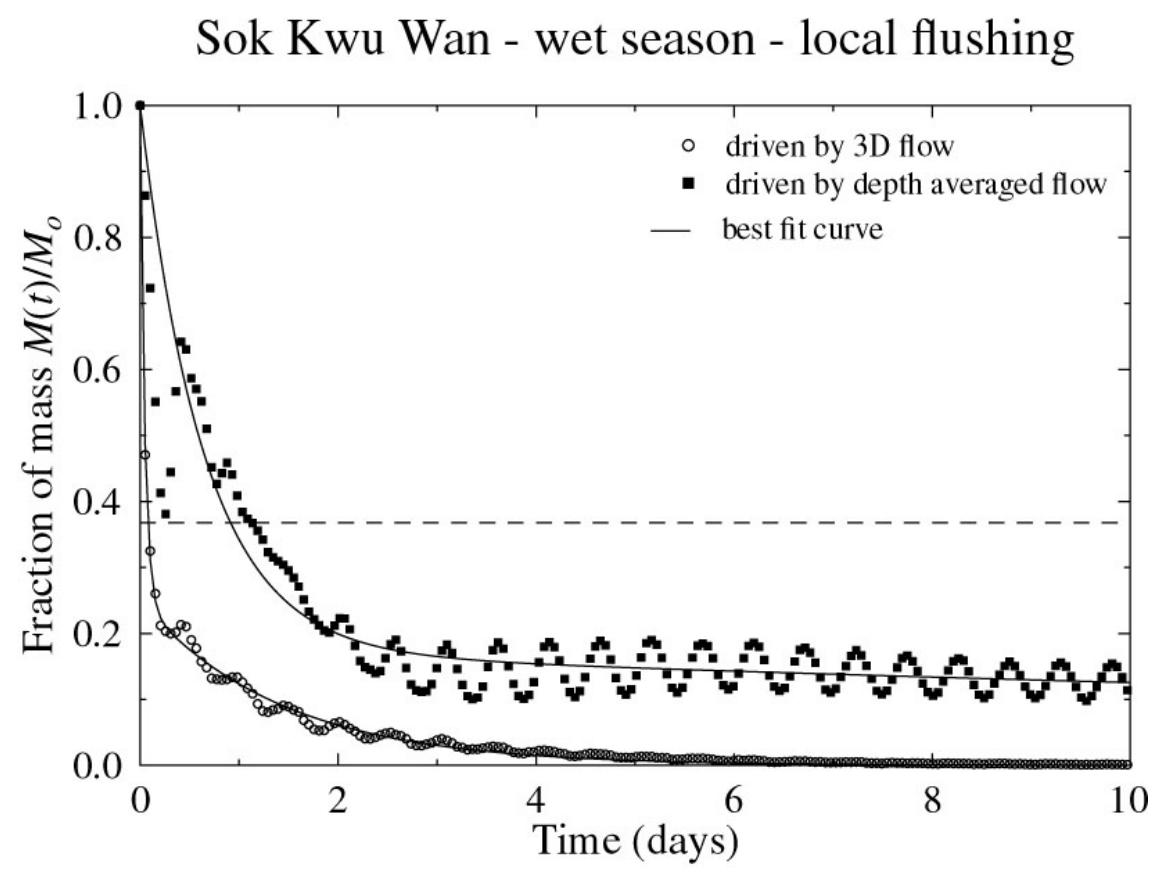

Fig. 2. Predicted mass removal in the fish farm inside Sok Kwu Wan for wet season (effect of density stratification) 


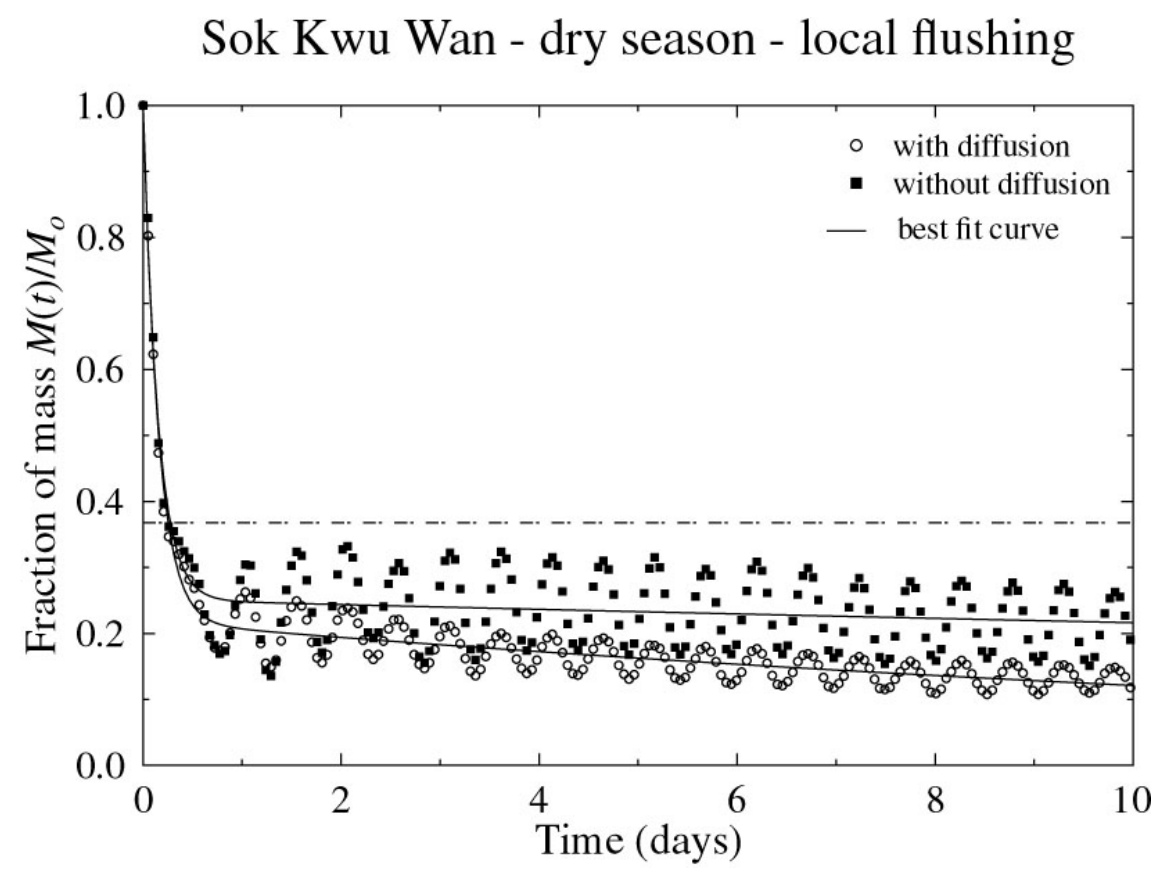

Fig. 3. Predicted mass removal in the fish farm inside Sok Kwu Wan for dry season (effect of turbulent diffusion) 


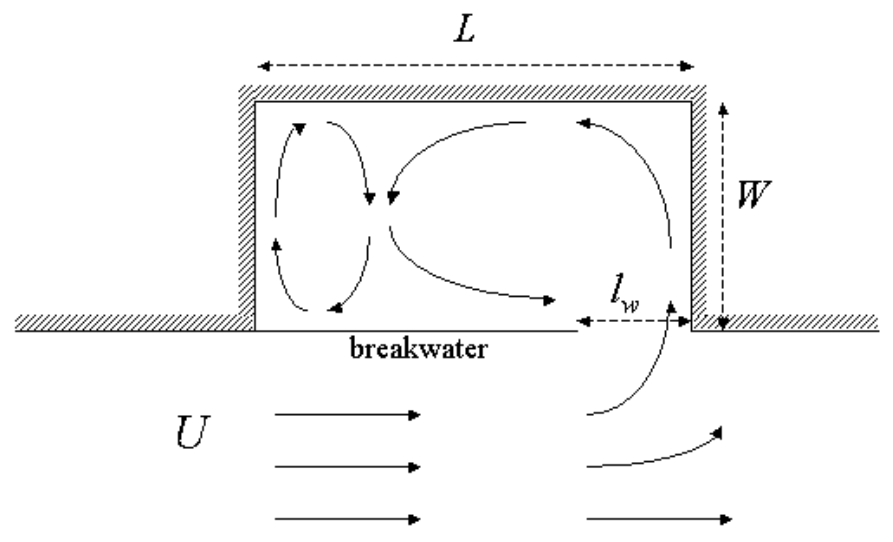

Fig. 4a). Schematic diagram of a laboratory experiment to determine residence time of semi-enclosed rectangular typhoon shelter.
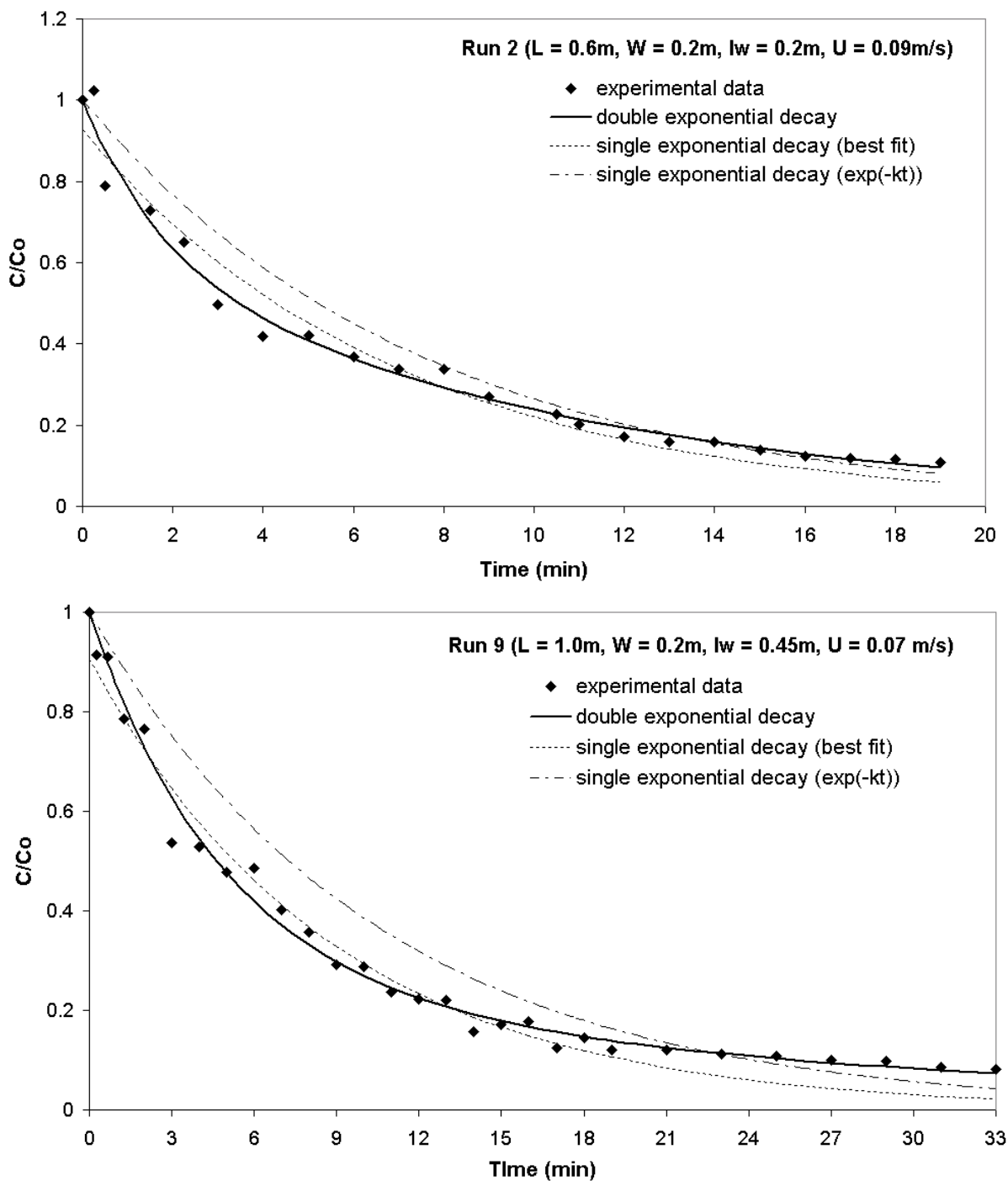

Fig. 4b). Measured tracer concentration with time in typhoon shelter (Run 2 and Run 9 of Li and Ip 1999) 


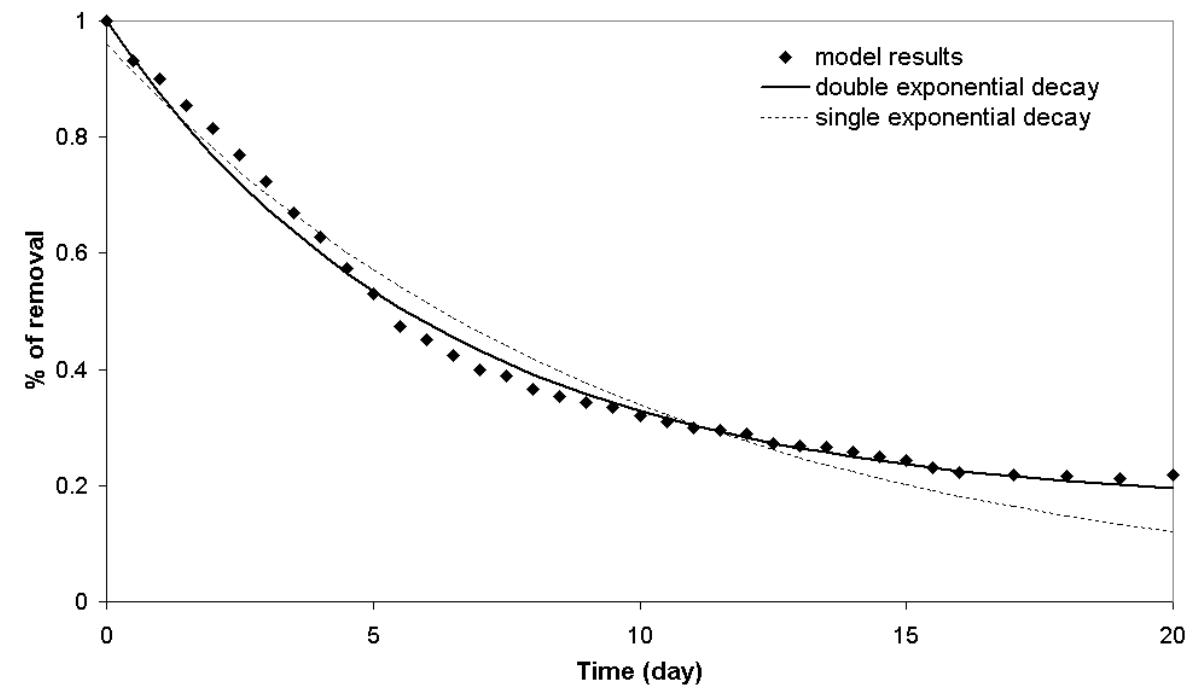

Fig. 5. Numerical determination of estuarine residence time (Mass removal curve based on Fig. 6 of Oliveria and Baptista 1996) 

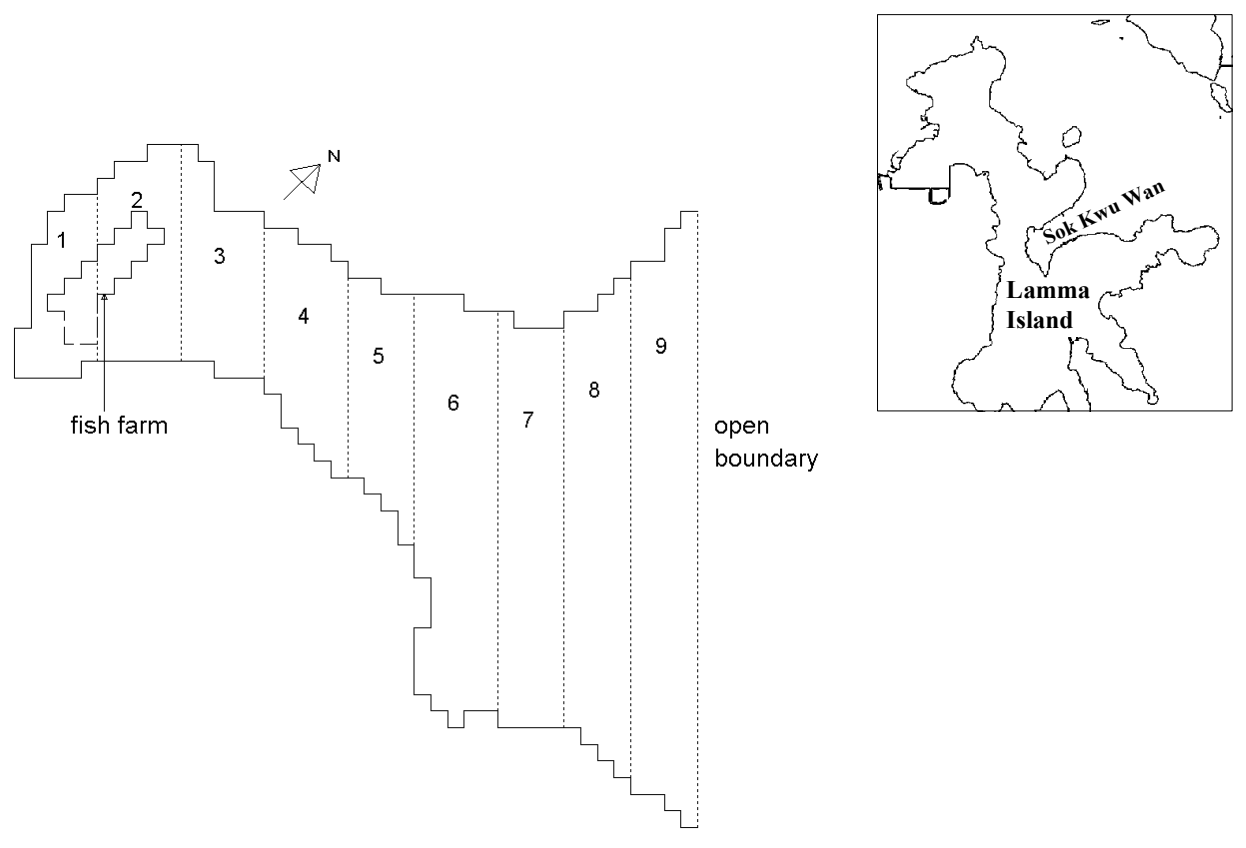

Fig. 6. Computational grid for Sok Kwu Wan, Lamma Island, Hong Kong showing segmentation for tidal flushing determination

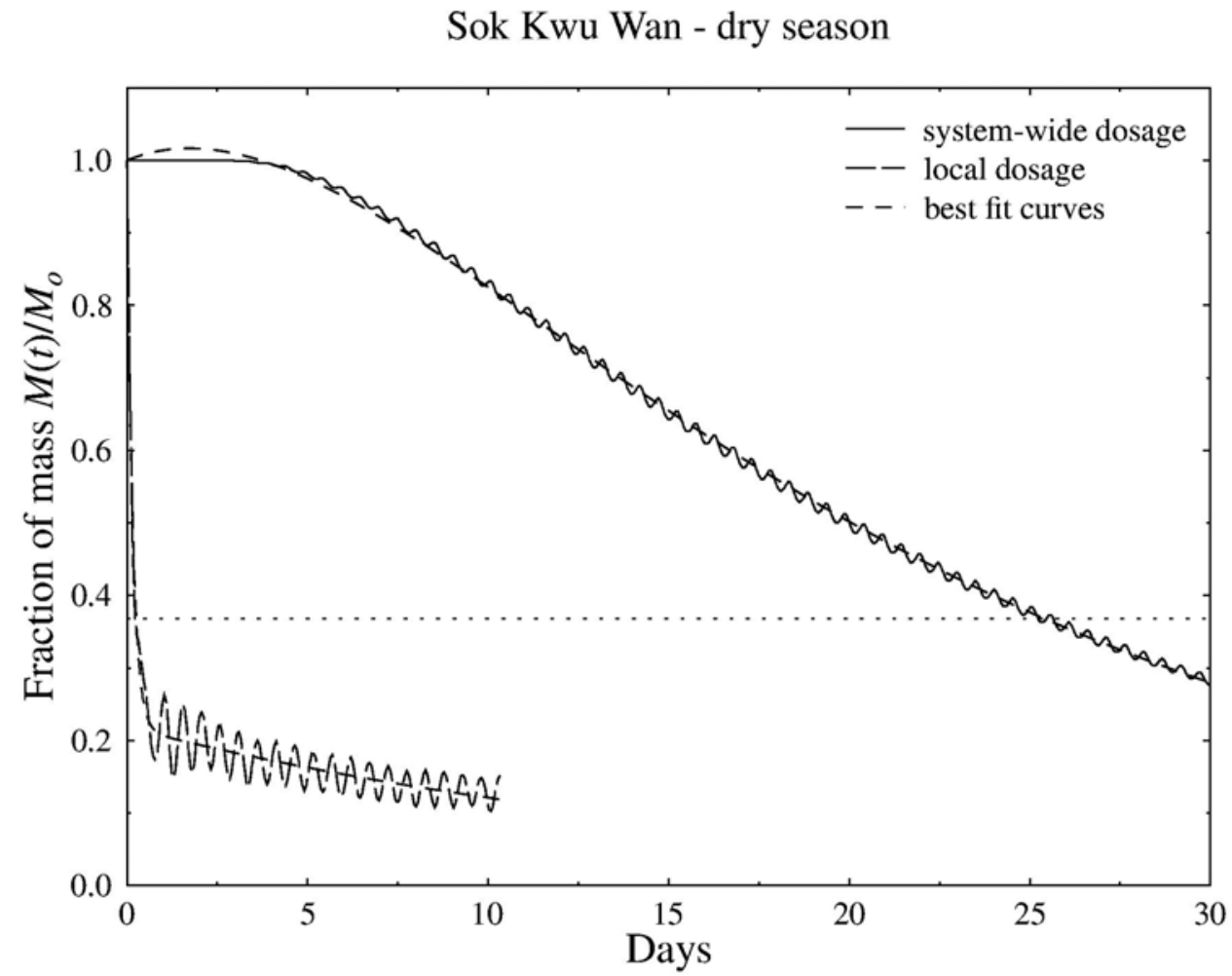

Fig. 7. Predicted tracer mass removal in segment 1 inside Sok Kwu Wan for dry season 

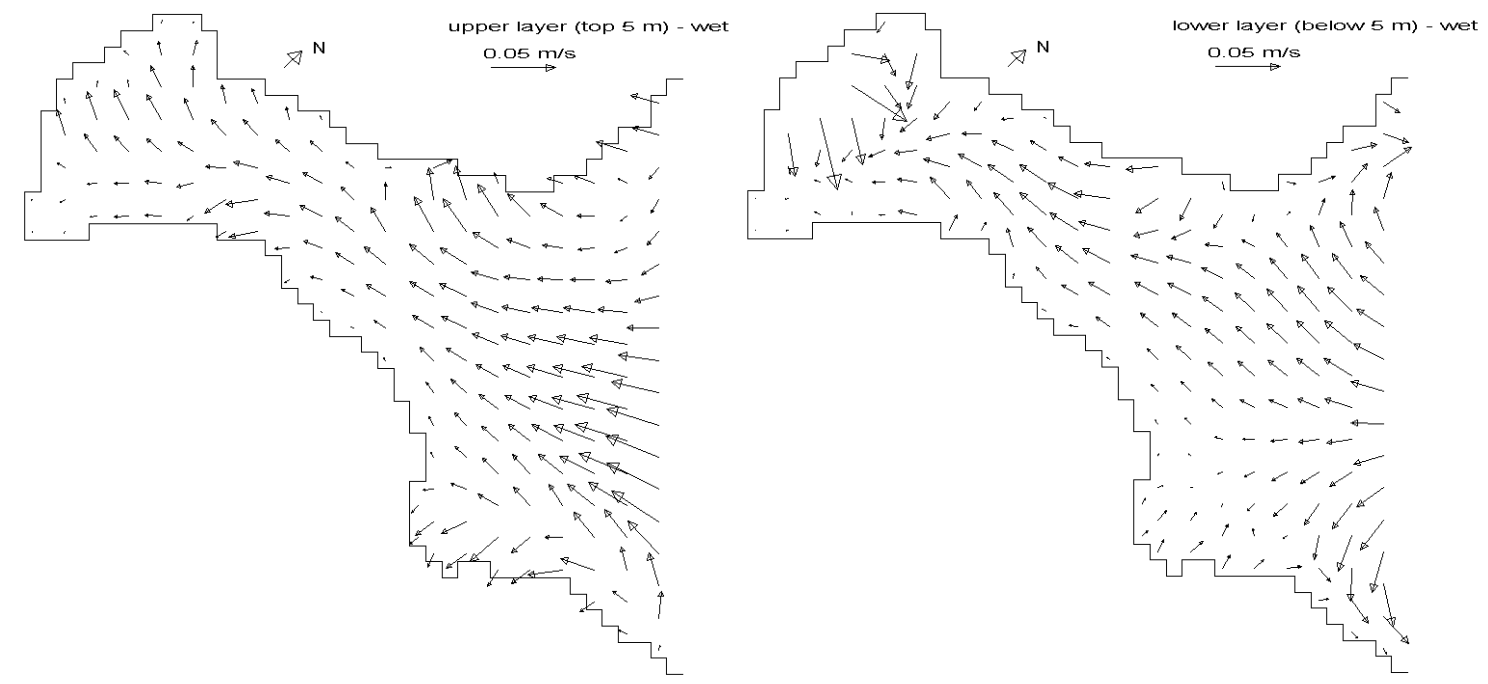

Fig. 8a) Computed peak flood flow in Sok Kwu Wan for wet season (HKU model)

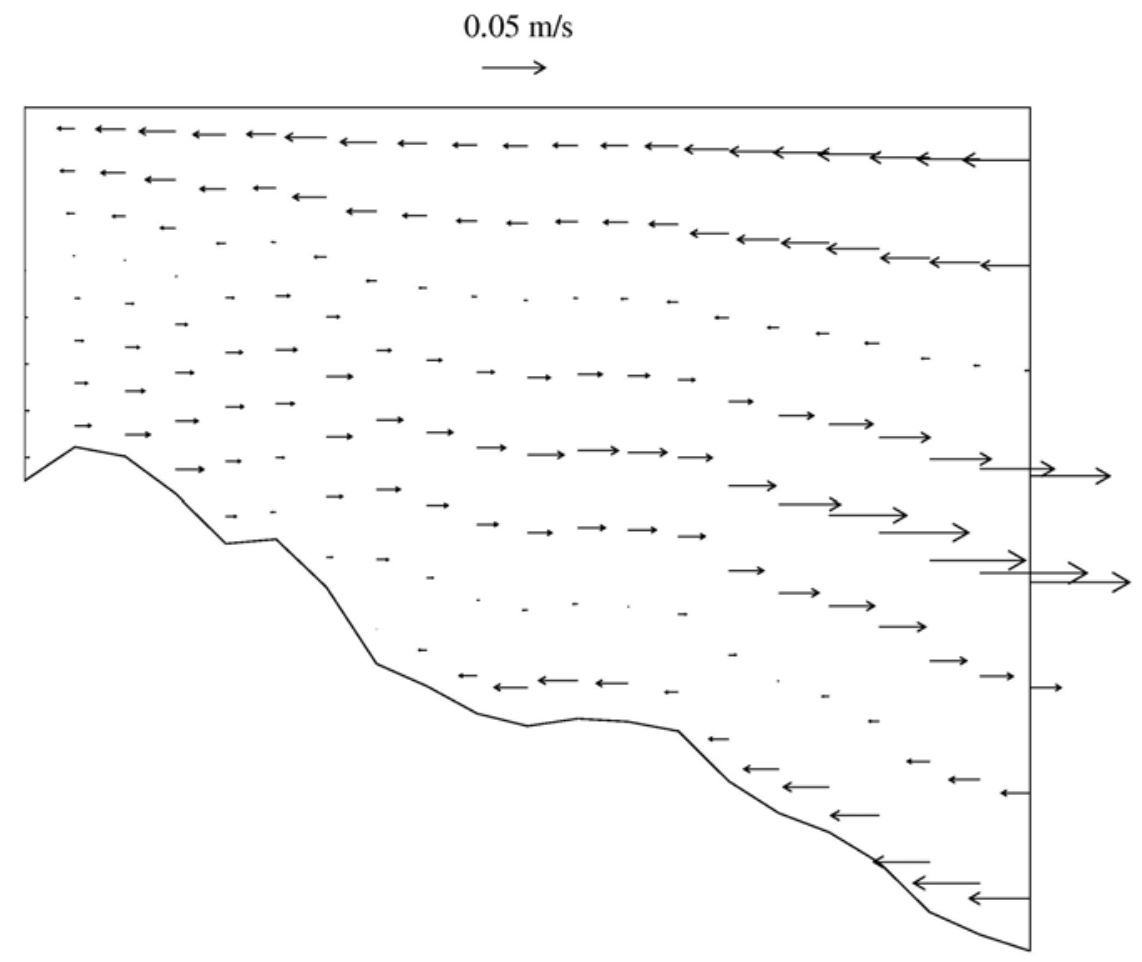

Fig. 8b) Tidally averaged $\mathrm{x}$-velocity along a longitudinal transect in Sok Kwu Wan for wet season (average water depth $=8 \mathrm{~m}$ to $17 \mathrm{~m}$ ) 


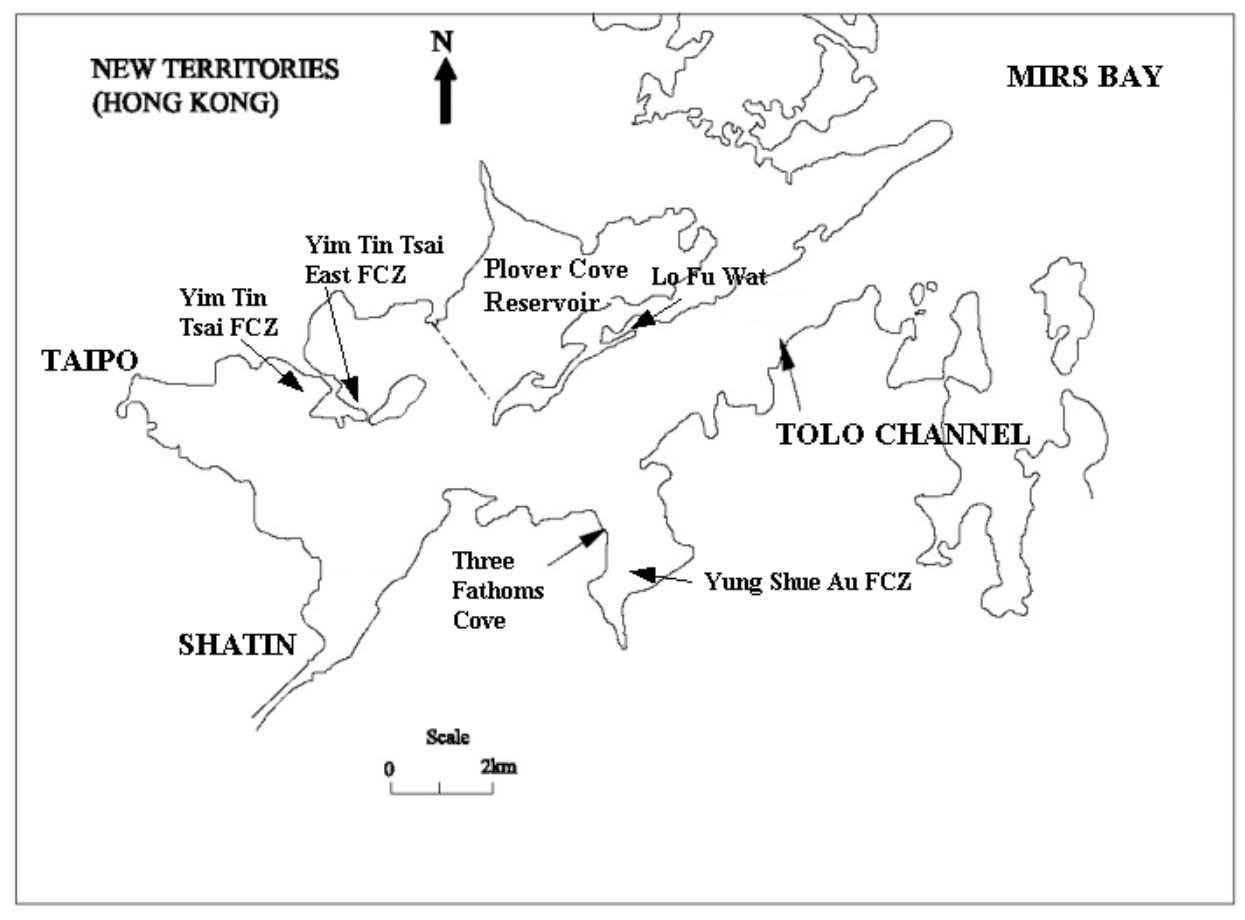

Fig. 9. Tolo Harbour and location of the fish culture zones 

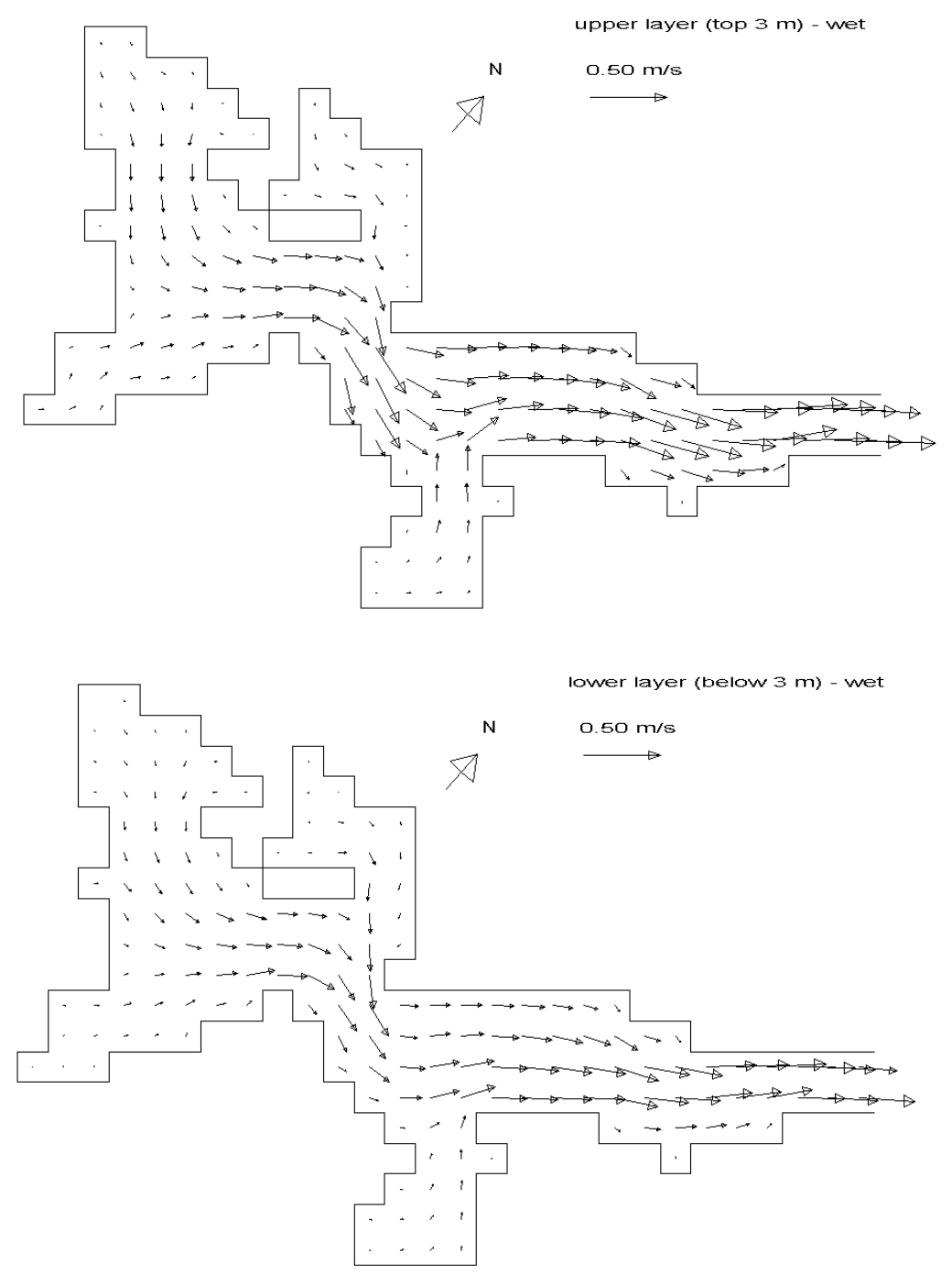

Fig. 10a) Computed peak ebb flow in Tolo Harbour for wet season

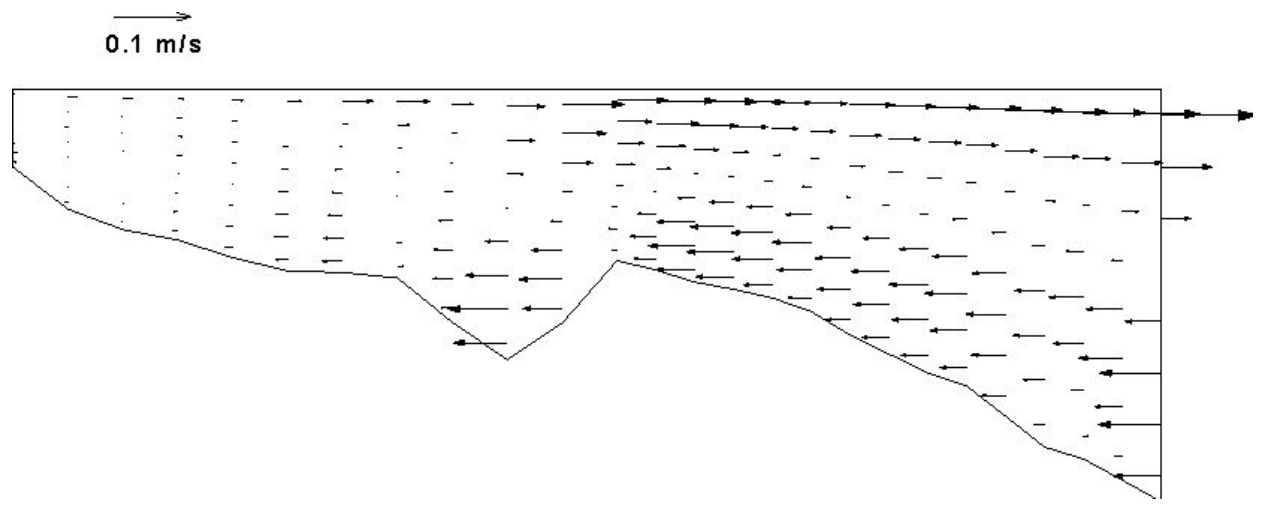

Fig. 10b) Tidally averaged $x$-velocity along a longitudinal transect in wet season (average water depth $=5 \mathrm{~m}$ to $25 \mathrm{~m}$ ) 


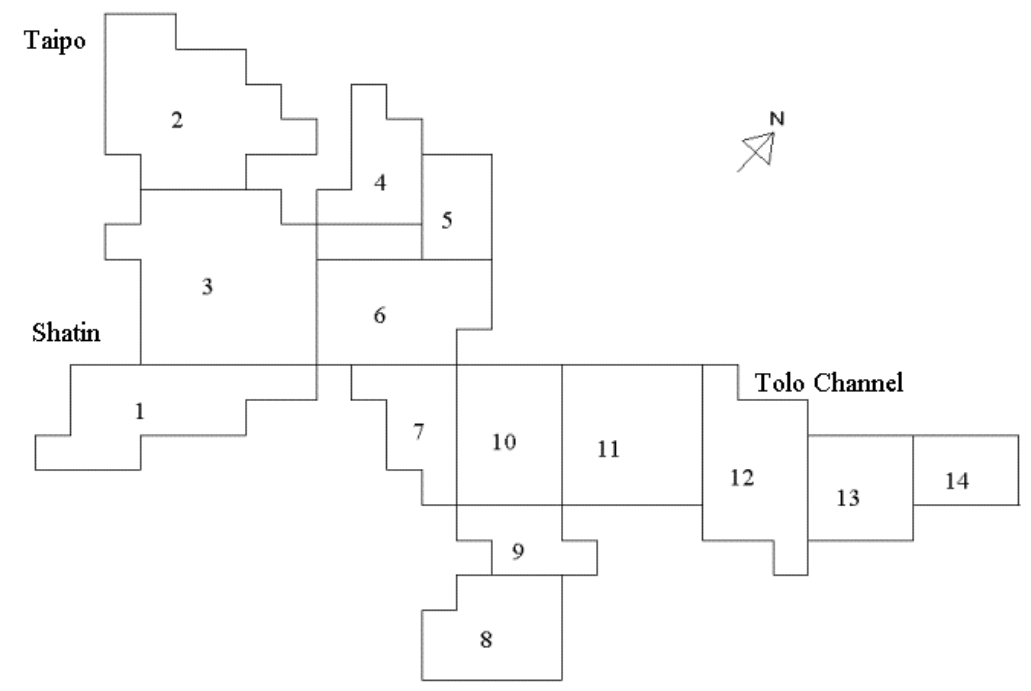

Fig. 11. Computational grid of Tolo Harbour showing segmentation for computing "system-wide" flushing 
Tolo harbour - wet season

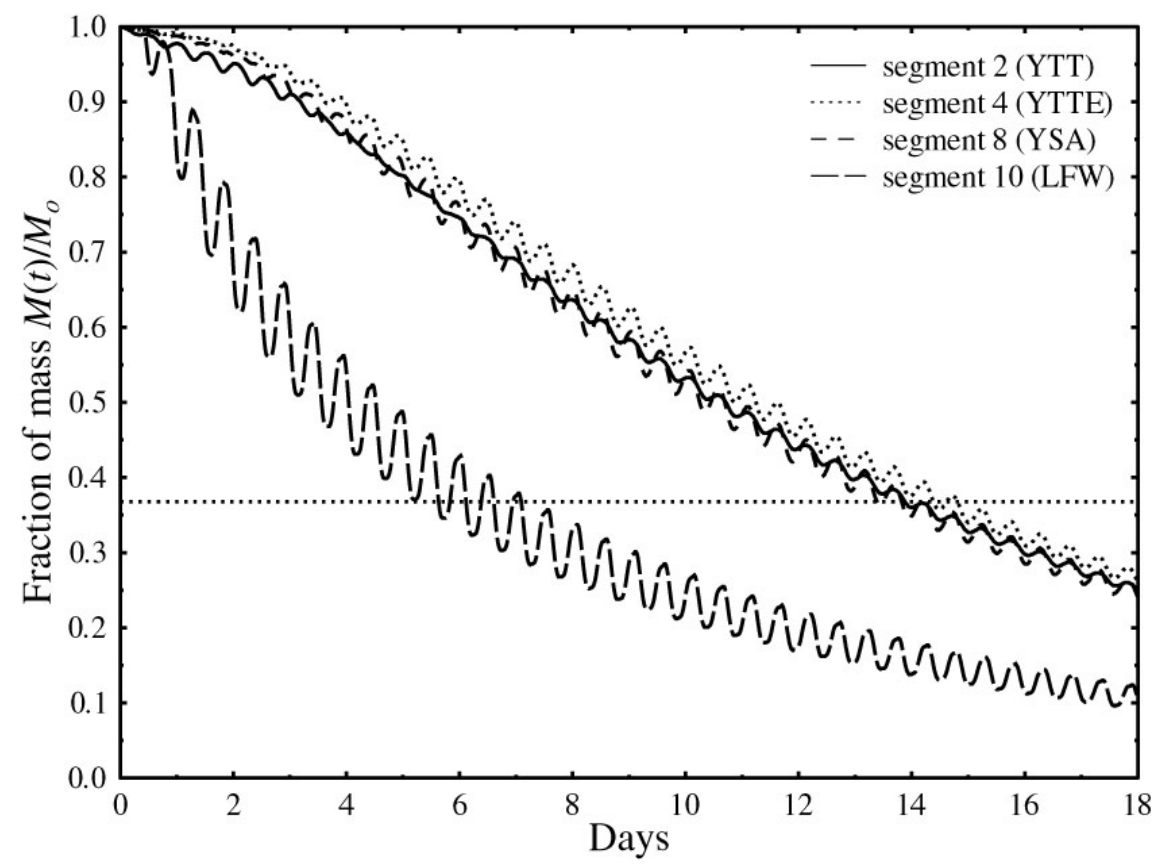

Fig. 12a). Variation of tracer mass in the segments with FCZ inside Tolo Harbour for wet season

Tolo harbour - dry season

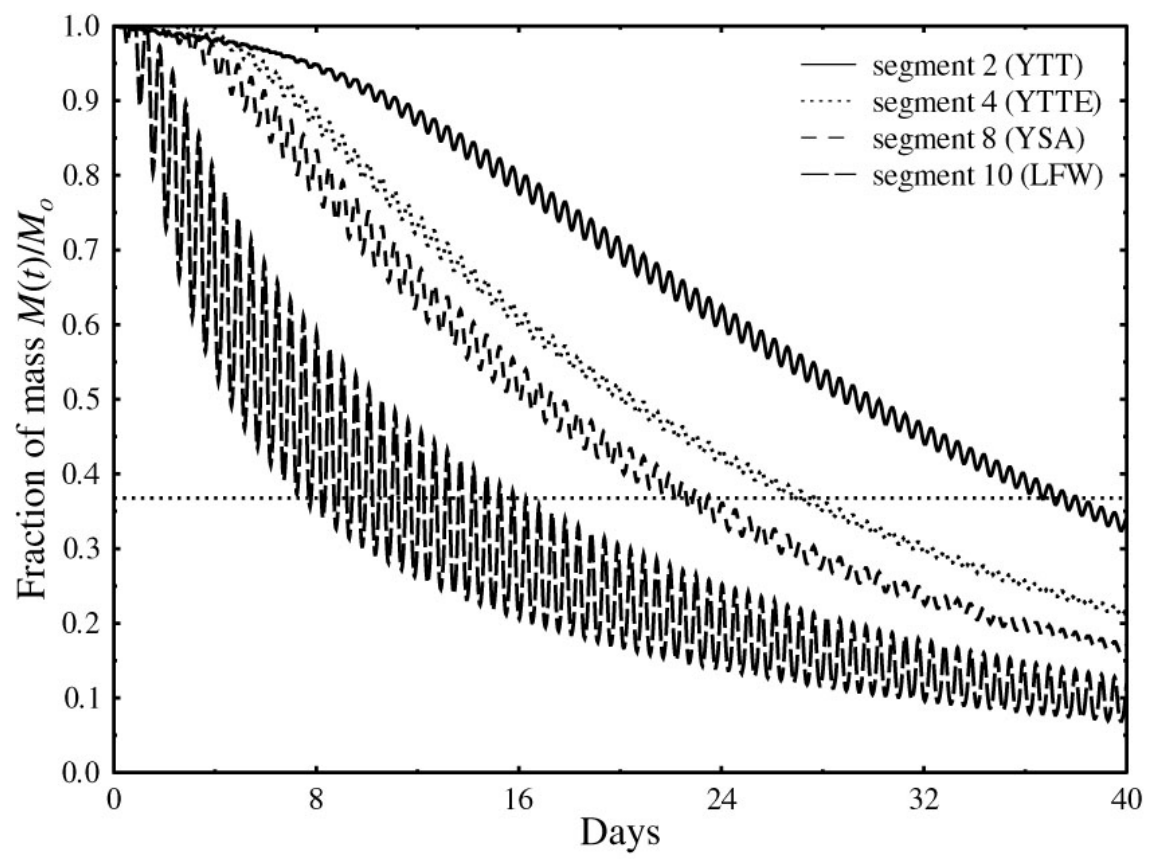

Fig. 12b). Variation of tracer mass in the segments with FCZ inside Tolo Harbour for dry season 